\title{
Capillary Electrophoresis Method Development for Simultaneous Determination of Atorvastatin and Ezetimibe from Solid Dosage Form
}

\author{
Mahesh Attimarad \\ Department of Pharmaceutical Sciences, College of Clinical Pharmacy, King Faisal University, Al-Ahsa, KSA.
}

\begin{abstract}
Purpose: A simple, rapid, validated capillary zone electrophoresis (CZE) was established for the simultaneous estimation of atorvastatin and ezetimibe from solid dosage form. Method: The separation of both the drugs was accomplished on fused silica capillary $(48 \mathrm{~cm} \times 50 \mu$ mi.d.) using background electrolyte consisting of $2 \mathrm{mM}$ borate buffer $(\mathrm{pH} 9.3)$ and methanol $(80: 20 \mathrm{v} / \mathrm{v})$ as BGE. All the capillary conditions were optimized and newly developed method was validated as per the $\mathrm{ICH}$ guidelines. Results: Good linear calibration was obtained for both the analytes ranging from 5 to $200 \mu \mathrm{g} / \mathrm{ml}$ and 2 to $20 \mu \mathrm{g} / \mathrm{ml}$ for atorvastatin and ezetimibe respectively. The limit of detection and quantification were less than $2 \mu \mathrm{g} / \mathrm{ml}$ for both the analytes. Repeatability and intra-day precision were well within the acceptable range. The accuracy was expressed as percent recovery, which is found to be between $98.20 \%$ to $100.41 \%$. Conclusion: The newly developed simple and validated CZE method was used for simultaneous determination of atorvastatin and ezetimibe from solid dosage form.
\end{abstract}

Key words: CZE, atorvastatin, ezetimibe, validation, simultaneous determination

Key Message: Newly developed analytical method is simple, rapid and validated, can be used for routine analysis of atorvastatin and ezetimibe, from formulations in pharmaceutical industries, clinical laboratories and analytical laboratories.

Correspondence :

Dr. Mahesh V. Attimarad,

Assistant Professor, Department of Pharmaceutical Sciences, College of Clinical Pharmacy, King Faisal University, P.O. 400. Al Ahsa, Saudi Arabia.

Phone no: +966553269799

Email: mattimarad@kfu.edu.sa, mattimarad@gmail.com

DOI: 10.5530/jyp.2017.9.22

\section{INTRODUCTION}

Atorvastatin calcium (ATC, Figure 1A), is a statin class compound, which enhance the HDL cholesterol level and decreases LDL cholesterol level along with triglycerides, hence used extensively in the management of hypercholesterolemia and associated medical complications. ${ }^{1}$ It acts by inhibiting theenzyme 3-hydroxy-3-methylglutaryl-coenzymeA(HMG$\mathrm{CoA}$ ) reductase, which is required for conversion of 3-hydroxy-3-methylglutaryl coenzyme A to mevalonate, a precursor of cholesterol. Ezetimibe (ETB, Figure 1B) is one of the best cholesterol absorption inhibitor, acts by inhibiting the absorption of cholesterol from the intestine, whereas the absorption of fat-soluble vitamins and triglycerides will not be affected. ${ }^{2}$ Simultaneous administration of both ATC and ETB provide better control of plasma cholesterol due to synergistic and dual mechanism of action. ${ }^{3}$

Different analytical methods are reported ${ }^{4-15}$ for the analysis of both ATC and ETB including spectroscopic methods, HPLC, LCMS, CZE and micellar electro-kinetic capillary electrophoresis (MEKC) methods from formulations and biological samples. However, only one capillary electrophoresis method $^{9}$ has been reported for simultaneous determination of ATC and ETB, which suffer from a disadvantage like long analysis time (more than $15 \mathrm{~min}$ ). CZE is widely used in pharmaceutical industries and clinical laboratories for the analysis of drugs from the pharmaceutical preparations and biological samples, due to several advantages such as fast analysis, less use of solvents, and separation with high resolutions of analytes. Hence, in this study rapid, simple and validated CZE procedure has been established for the simultaneous determination of ATC and ETB form solid dosage forms.

\section{MATERIALS AND METHODS}

\section{Chemical and reagents}

Atorvastatin calcium, ezetimibe and pravastatin sodium were purchased from the Biokemix, India. Solid dosage form consisting of $20 \mathrm{mg}$ ATC and $10 \mathrm{mg}$ ETB per tablet were purchased from the market. Analytical grade methanol, sodium hydroxide and sodium tetra borate were parched From sigma Aldrich. Deionized water obtained from Milli Q system was used for preparing standard solutions and BGE.

\section{Apparatus}

All trials were executed on Agilent CE instrument equipped with diode array detector. The analytes separation was achieved on fused silica capillary (Agilent Technologies). with inner diameter of $50 \mu \mathrm{M}$, using BGE consists of borate buffer $(2 \mathrm{mM})$ and methanol $(80: 20 \mathrm{v} / \mathrm{v})$. Total length of the capillary was $52 \mathrm{~cm}$ and the detection window was $8.4 \mathrm{~cm}$ from the vent end of the capillary. The new capillary tube was activated by pumping $1.0 \mathrm{M}$ sodium hydroxide for $20 \mathrm{~min}$, deionized water for $10 \mathrm{~min}$ and BGE for $10 \mathrm{~min}$ in sequence. Every day just before starting the experiment capillary tube was activated by flushing $0.1 \mathrm{M}$ sodium hydroxide, deionized water and BGE for 15, 10 and 5 min respectively. Wavelength of $210 \mathrm{~nm}$ was set for the detection of analytes. After every three runs the capillary tube was washed with $0.1 \mathrm{M} \mathrm{NaOH}$, water and BGE for 1, 2 and 2 min respectively. The optimized electrophoresis conditions were applied voltage was $25 \mathrm{kV}$, capillary oven was set at $25^{\circ} \mathrm{C}$, samples were injected by hydrodynamic pressure at 50 bar for $5 \mathrm{~s}$. 


\section{Solutions}

Standard stock solutions ( $1 \mathrm{mg} / \mathrm{ml}$ ) of ATC, ETB and internal standard (IS) pravastatin sodium were prepared distinctly by dissolving accurately weight quantity of drugs (100 mg each) in $50 \mathrm{ml}$ of methanol in $100 \mathrm{ml}$ volumetric flask and then water was added up to the mark. The stock solutions were stored in refrigerator at $4^{\circ} \mathrm{C}$. Working standard solutions were prepared just before by diluting with BGE to obtain required concentration range.

For the sample preparation 20 tablets were weighed separately and crushed into fine powder with mortar and pestle. An accurately weighted amount of powder corresponding to $20 \mathrm{mg}$ of ATC and 10mg of ETB was transferred in to $100 \mathrm{ml}$ graduated flask consisting of $50 \mathrm{ml}$ methanol. The flask was sonicated for $20 \mathrm{~min}$ to complete dissolve the analytes and the volume was made up to the mark with water. The sample solution was filtered using $0.45 \mu \mathrm{m}$ filter paper. Prior to analysis, the sample solution was diluted with BGE to get the final concentration in the linearity range.

\section{RESULT AND DISCUSSION}

Method development: Newly developed CZE method was able estimate both the analytes from the combined formulation with good resolution. The Figure 2 represents the electrophoregram of standard and sample solutions. The migration of the anyltes was rapid under optimized electrophoresis conditions and it was found to $4.03 \mathrm{~min}, 5.23 \mathrm{~min}$ and 6.05 min for IS, ETB and ATC respectively.

Different experimental conditions were adopted to optimize the separation and quantification of both analytes in reasonable time with good resolution. Phosphate, borate and acetate buffer systems were tested as BGE at neutral and basic $\mathrm{pH}$. Analysis time was longer with the phosphate and acetate buffer. Borate buffer provided the complete separationof both the analytes with good resolution. The effect of $\mathrm{pH}$ was studied in the range of pH 7 to 10 using $2 \mathrm{mM}$ borate buffer and methanol. Migration time was reduced with increase in the $\mathrm{pH}$, with $\mathrm{pH} 9.3$ analytes were separated in reasonable time, Hence $\mathrm{pH}$ was set at 9.3. Buffer concentration plays important role in separation of analytes and migration of EOF. Increase in the buffer concentration showed increasing in the analysis time, hence buffer concentration 1 to $4 \mathrm{mM}$ was selected for further investigation. A $2 \mathrm{mM}$ concentration of borate buffer demonstrated short analysis time along with best peak shape, and lower current, hence selected as optimum. Addition of organic modifier in BGE was advantageous because it reduced noise and changes viscosity of EOF. As ATC was insoluble in acetonitrile methanol in three concentrations (10, 20 and 30\%) was investigated. The results showed that $20 \%$ methanol was adequate for the complete separation of both analytes without interference from the EOF. The instrument parameters such applied voltage, column temperature and sample injection time were investigated using $2 \mathrm{mM}$ borate buffer and methanol $(80 ; 20 \mathrm{v} / \mathrm{v})$ Voltage in the range of 5 to $30 \mathrm{kV}$ and temperature in the range of 2035 were investigated for their effect on migration time of drugs. The symmetric peaks and short analysis time was observed with $55 \mathrm{kV}$ applied voltage at $25^{\circ} \mathrm{C}$ column temperature. Hence, these values were set for the further analysis. Usually hydrodynamic injection system was used for injection of samples. Peak area and peak height depends upon the injection time. Hence, sample injections at $50 \mathrm{mbar}$ for different time between 2 to $10 \mathrm{~s}$ was investigated. Good peak shapes for both the analytes were observed with $5 \mathrm{~s}$ injection period. Therefore, injection time of $5 \mathrm{~s}$ was used throughout the experiment.

Method validation: Use of internal standard has been recommended to avoid injection and voltage errors, in capillary electrophoresis. In the present study pravastatin has been selected as internal standard because it is closely related to ATC and gave good peak shape and resolution. The proposed CZE method was validated in terms of linearity, limit of detection (LOD), limit of quantification (LOQ), precision and accuracy as per the ICH requirements.

Linearity was studied by injecting five concentrations in the range of 5 to $200 \mu \mathrm{g} / \mathrm{ml}$ and 2 to $20 \mu \mathrm{g} / \mathrm{ml}$ for ATC and ETB respectively. $50 \mu \mathrm{g} / \mathrm{ml}$ pravastatin was used as internal standard. Calibration curve was prepared by plotting concentration against peak area ratio of analytes and IS. Linearity equations were used for the determination of concentration in sample solutions.

The LODs and LOQs of the CZE procedure were determined by signal to noise ratio criterion $\mathrm{S} / \mathrm{N}=3$ and $\mathrm{S} / \mathrm{N}=10$ respectively. LODs were found to $0.42 \mu \mathrm{g} / \mathrm{ml}$ and $0.60 \mu \mathrm{g} / \mathrm{ml}$, whereas LOQs were $1.23 \mu \mathrm{g} / \mathrm{ml}$ and $1.84 \mu \mathrm{g} / \mathrm{ml}$ for ATC and ETB respectively. (Table 1)

Precision of the assay procedurewas investigated in terms of repeatability and inter day precision. Previously analyzed formulation was spiked with standard solution at concentrations of $10 \mu \mathrm{g} / \mathrm{ml} \mathrm{ETB}$ and $100 \mu \mathrm{g} / \mathrm{ml}$ of ATC followed by IS. Than the solutions were analyzed six times on the same day for the repeatability and for inter day precisionsamples were analyzed on three consecutive days. The result showed less than 2 percent relative standard deviation (\%RSD) indicating the good precision of the method (Table 1).

The accuracy of the method was investigated by determining the mean recoveries of added analytes from the formulations at three varied concentrations covering the complete linearity range. The mean recoveries were found to be close to $100 \%$ for both ATC and ETB indicating the accuracy of newly developed CZE procedure.(Table 2).

Table 1: System suitability and validation parameters of ETB and ATC

\begin{tabular}{ccc}
\hline Analytical Parameters & ETB & ATC \\
\hline Retention Time $(\mathrm{min})$ & 5.23 & 6.05 \\
Resolution $(\mathrm{min})$ & $5.02^{\mathrm{a}}$ & $4.12^{\mathrm{b}}$ \\
Peak symmetry & 0.97 & 1.03 \\
Linearity range $(\mu \mathrm{g} / \mathrm{mL})$ & $2-20$ & $5-200$ \\
Intercept & 0.0058 & -0.037 \\
Slope & 0.0676 & 0.0117 \\
Correlation coefficient $(\mathrm{r})$ & 0.9982 & 0.9956 \\
LOD ( $\mu \mathrm{g} / \mathrm{mL})$ & 0.42 & 0.60 \\
LOQ ( $\mu \mathrm{g} / \mathrm{mL})$ & 1.23 & 1.84 \\
Repeatability (\% RSD $\mathrm{n}=6)$ & 0.71 & 1.37 \\
Intra day Precision $(\% \mathrm{RSD}, \mathrm{n}=3$ days) & 1.39 & 1.46 \\
Assay $(\%)$ & 98.83 & 99.16 \\
\hline
\end{tabular}

${ }^{a}$ Resolution calculated between IS and ETB peaks

${ }^{\mathrm{b}}$ Resolution calculated between ETB and ATC peaks

'determination of the drugs form their formulations

Table 2: Accuracy results

\begin{tabular}{cccccc}
\hline Drug & $\begin{array}{c}\text { Added } \\
(\mu \mathrm{g} / \mathrm{mL})\end{array}$ & $\begin{array}{c}\text { Found }^{\mathrm{a}} \\
(\mu \mathrm{g} / \mathrm{mL})\end{array}$ & $\begin{array}{c}\text { Accuracy } \\
(\%)\end{array}$ & $\begin{array}{c}\text { RSD } \\
(\%)\end{array}$ & $\begin{array}{c}\text { Bias }^{\mathrm{b}} \\
(\%)\end{array}$ \\
\hline \multirow{2}{*}{ ETB } & 5 & $4.91 \pm 0.06$ & 98.20 & 1.20 & -1.80 \\
& 10 & $9.87 \pm 0.15$ & 98.70 & 1.50 & -1.30 \\
& 15 & $14.89 \pm 0.21$ & 99.27 & 1.40 & -0.73 \\
\multirow{2}{*}{ ATC } & 25 & $24.86 \pm 0.43$ & 99.44 & 1.72 & 0.56 \\
& 75 & $75.31 \pm 0.92$ & 100.41 & 1.23 & -0.41 \\
& 100 & $99.32 \pm 1.03$ & 99.32 & 1.03 & -0.68 \\
\hline
\end{tabular}

a: Mean $(n=3) \pm$ SD. RSD: Relative standard error by Deviation

b:Bias $=($ measured concentration-Added concentration/added concentration $) 100$ 
<smiles>CC(C)c1c(C(=O)Nc2ccccc2)c(-c2ccccc2)c(-c2ccc(F)cc2)n1CCC(O)CC(O)CC(=O)O</smiles>

(a)<smiles>CCC(C)C(=O)OC1CC(O)C=C2C=CC(C)C(CCC(O)CC(O)CC(=O)O)C21</smiles>

(b)

Figure 1: Chemical structures of atorvastatin calcium (a), ezetimibe (b) and pravastatin sodium (c).

Specificity of the CZE procedure was evaluated by matching the electropherograms developed from solutions of laboratory mixed analytes and formulations. It is evident form the Figure 2 that the new method is specific, as no extra peaks were observed for the additives of the formulation.

\section{Assay of ATC and ETB from formulation}

Newly developed CZE procedure was effectively used for the simultaneous evaluation of ATC and ETB from pharmaceutical preparations. The assay was performed by analyzing three independent solutions of the formulation and the results were tabulated in Table 1. Satisfactory results were obtained for both the analytes and the quantity of the analytes were in agreement with the label claim.

\section{CONCLUSIONS}

A simple, accurate and precise capillary zone electrophoresis procedure was established for the simultaneous estimation of atorvastatin and ezetimibe from solid dosage form. Both the analytes were separated with high resolution within $6.5 \mathrm{~min}$. Finally, the CZE procedure was applied for simultaneous estimation of atorvastatin and ezetimibe from tablets. Newly developed procedure exhibited high specificity as no additional peaks were observed for the formulation additives. Hence, newly developed CZE procedure can be adopted for repetitiveexaminationof atorvastatin and ezetimibe in raw material and formulations.

\section{ACKNOWLEDGEMENTS}

The authors thank Deanship of Scientific Research, King Faisal University, Saudi Arabia for funding this project (\# 175012). Authors also thank Dean College of Clinical Pharmacy for providing the facilities.

\section{CONFLICT OF INTEREST}

No conflict of interest are declared.

\section{ABBREVIATIONS USED}

BGE: Background electrolyte; ICH: International Conference on Harmonisation; CZE: Capillary Zone Electrophoresis; EOF: electroosmotic flow.

\section{REFERENCES}

1. McTaggart $F$, Jones $P$. Effects of statins on high-density lipoproteins: a potentia contribution to cardiovascular benefit. Cardiovasc Drugs Ther. 2008;22:321-8.

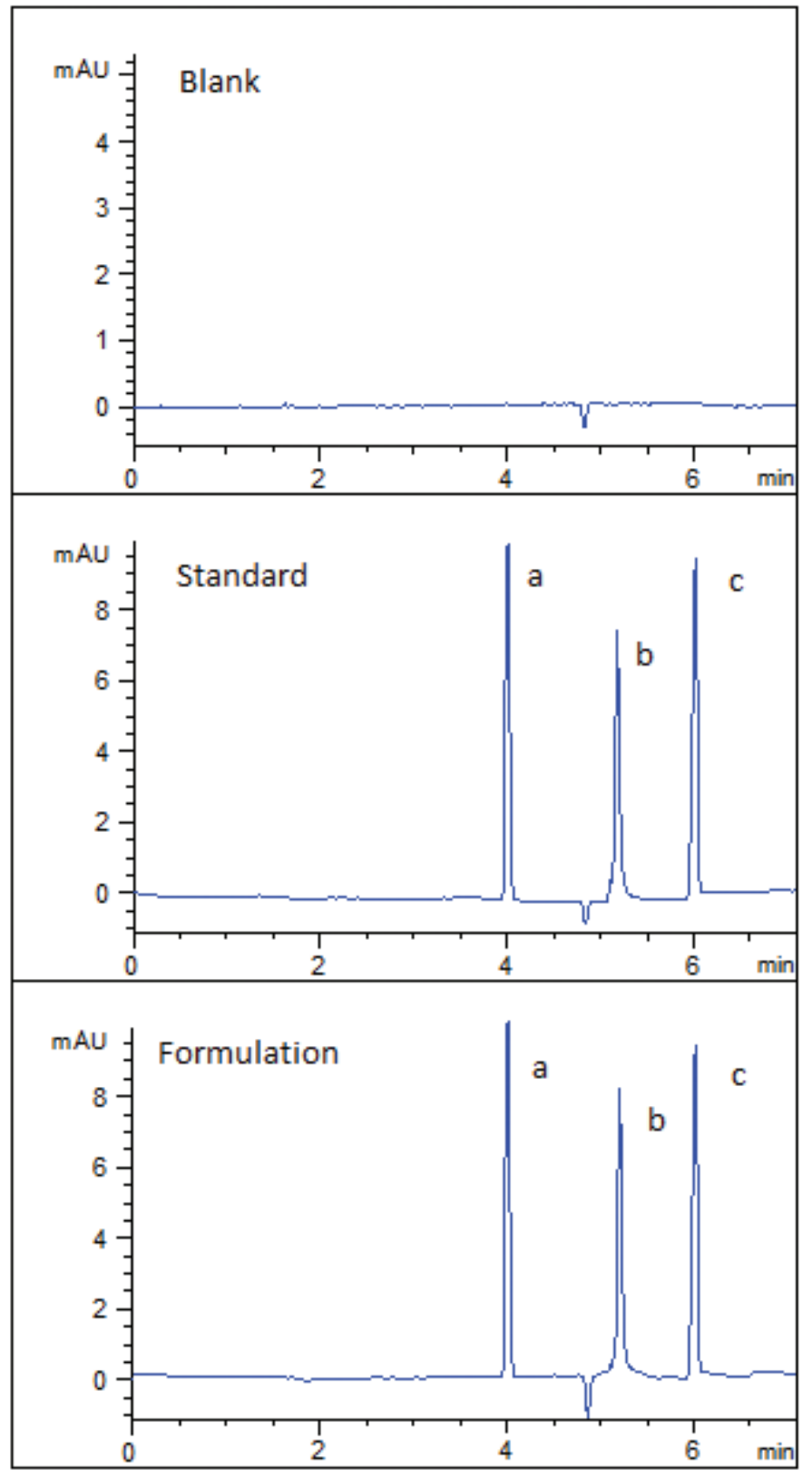

Figure 2: The electropherograms of Blank, standard and formulation solutions. Electrophoretic conditions:2mM Borate buffer, $(\mathrm{pH} \mathrm{9.3)} \mathrm{and}$ methanol ( $80 \%: 20 \% \mathrm{v} / \mathrm{v})$., fused silica capillary column $(55 \mathrm{~cm}$ length, $50 \mu \mathrm{m}$ i.d.) hydrodynamic injection time of $5 \mathrm{~s}$ at pressure of $50 \mathrm{mbar}$, separation voltage of $25 \mathrm{kV}$ and column temperature of $25^{\circ} \mathrm{C}$, at $210 \mathrm{~nm}$. $\mathrm{a} ; \mathrm{IS}, \mathrm{b}$; ETB, and c; ATC.

2. Bruckert E, Giral P, Tellier P. Perspectives in Cholesterol-Lowering Therapy. The Role of Ezetimibe, a New Selective Inhibitor of Intestinal Cholesterol Absorption. Circulation. 2003;107:3124.

3. Conard SE, Bays HE, Leiter LA, Bird SR, Rubino J, Lowe RS, et al. Efficacy and safety of ezetimibe added on to atorvastatin $(20 \mathrm{mg})$ versus uptitration of atorvastatin (to $40 \mathrm{mg}$ ) in hypercholesterolemic patients at moderately high risk for coronary heart disease. Am J Cardiol. 2008;102:1489-94.

4. Patel A, Macwana C, Parmar V, Patel S. Simultaneous determination of atorvastatin calcium, ezetimibe, and fenofibrate in a tablet formulation by HPLC. J AOAC Int. 2012;95(2):419-23.

5. El-Bagary RI, Elkady EF, El-Sherif ZA, Kadry AM. LC-MS-MS simultaneous determination of atorvastatin and ezetimibe in human plasma. J Chromatogr Sci. 2014;52(8):773-80. 
6. Das R, Pal TK. Validation of liquid chromatography-tandem mass spectrometry for mevalonate in human plasma: Incompetent effects between treated atorvastatin and its combination with olmesartan in cardiovascular patients. J Young Pharma. 2014;6(2):50-7.

7. Galani VJ, Vyas M. In vivo and In vitro Drug Interactions Study of Glimepride with Atorvastatin and Rosuvastatin. J Young Pharma. 2010;2(2):196-200.

8. Ilango K, Kumar PS. Validated spectrophotometric methods for the simultaneous determination of telmisartan and atorvastatin in bulk and tablets. Pharmaceutical Methods. 2012;3(2):112-6.

9. Alshehri MM. A validated capillary electrophoresis method for simultaneous determination of ezetimibe and atorvastatin in pharmaceutical formulations. Saudi Pharmacel J. 2012;20(2):143-8.

10. Dixit RP, Barhate CR, Padhye SG, Viswanathan CL, Nagarsenker MS. Stability Indicating RP-HPLC Method for Simultaneous Determination of Simvastatin and Ezetimibe from Tablet Dosage Form. Indian J Pharm Sci. 2010;72(2):204-10.
11. Metreyi S, Deepali M, Mahadik M, Kadam S, Dhaneshwar S. UV and three derivative spectrophotometric methods for determination of ezetimibe in tablet formulation. Indian J Pharm Sci. 2008;70(2):258-60.

12. Abdelwahab NS. EL-Zeiny BA. Tohamy SI. Two spectrophotometric methods for simultaneous determination of some antihyperlipidemic drugs. J Pharm Anal. 2012;2(4):279-84.

13. Seshachalam U, Kothapally CB. HPLC analysis for simultaneous determination of atorvastatin and ezetimibe in pharmaceutical formulations. J Liq Chromatogr Related Technol. 2008;1(5):714-21.

14. Aiyalu R, Mani K. HPTLC method development, validation, and stress degradation studies for atorvastatin and ezetimibe in multicomponent tablet dosage form. Med Chem Res. 2012;21(7):1297-301.

15. MacWana CR, Patel AJ, Parmar VM. Simultaneous HPTLC analysis of atorvastatin calcium, ezetimibe, and fenofibrate in tablet. J Liq Chromatogr Related Technol. 2012;35(4):524-32.

Article History: Submission Date: 22-06-16; Revision Date: 19-07-16; Accepted Date: 07-08-16.

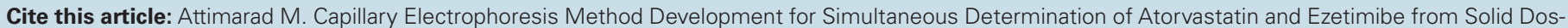
age Form. J Young Pharm. 2017;9(1):120-3. 